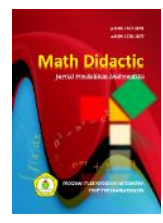

MATH DIDACTIC: JURNAL PENDIDIKAN MATEMATIKA

Volume 5 Nomor 1, Januari - April 2019, halaman 13 - 22

Tersedia Daring pada http://jurnal.stkipbjm.ac.id/index.php/math

\title{
ETNOMATEMATIKA PADA PERLENGKAPAN TARI BAGIPANG MASYARAKAT PANTAI HAMBAWANG TIMUR
}

\section{ETHNOMATHEMATICS ON BAGIPANG DANCE EQUIPMENT FROM PANTAI HAMBAWANG TIMUR PEOPLE}

Sarmina Dewi, Abdul Jabar, Rahmita Yuliana Gazali

Program Studi Pendidikan Matematika STKIP PGRI Banjarmasin

sarminadewi64@gmail.com, abdul.jabar.bjm@gmail.com, rahmitayulianagazali@yahoo.com

\begin{abstract}
Abstrak: Salah satu kebudayaan tarian tradisional yang masih dilestarikan masyarakat Pantai Hambawang Timur adalah tari bagipang. Tari bagipang merupakan warisan turun-temurun dari nenek moyang yang perlu dilestarikan. Penampilan tarian ini memakai seekor kuda-kudaan yang terbuat dari bambu dengan tata rias dan tata busana yang khas, dan diiringi dengan musik gamelan. Tujuan dalam penelitian ini adalah mengetahui bentuk geometri dan konsep matematika yang ada pada perlengkapan tari bagipang, metode penelitian ini adalah kualitatif dengan pendekatan etnografi. Hasil penelitian menunjukkan bahwa terdapat bentuk-bentuk geometri yang beraturan pada perlengkapan tari bagipang, yaitu: (1) persegi panjang; (2) belah ketupat; (3) trapesium sama kaki; (4) segitiga sama sisi dan sama kaki; (5) lingkaran; (6) bola; dan (7) setengah bola, adapun bentuk geometri tak beraturan terdapat pada bentuk kuda gipangnya. Ada konsep-konsepmatematika pada perlengkapan tari bagipang, yaitu:(1) bilangan; (2) fungsi konstan; (3) fungsi periodik; (4) refleksi; (5) himpunan; (6) volume benda putar; (7) pengukuran volume dengan satuan liter; (8) volume dengan satuan gelas; dan (9) volume kerucut terpancung dengan satuan gelas. Salah datu contoh konsep matematika adalah konsep bilangan. Angka yang kita kenal adalah 0, 1, 2, 3, 4, 5, 6, 7, 8, 9. Sedangkan bilangan adalah susunan dari angka-angka yang memiliki nilai tertentu. Bilangan terdiri dari satu angka yang kita kenal dengan satuan, bilangan dua angka yang kita kenal dengan puluhan, bilangan tiga angka yang kita kenal dengan ratusan, dan seterusnya.
\end{abstract}

Kata Kunci: etnomatematika, perlengkapan tari bagipang, masyarakat Pantai Hambawang Timur

Abstract: One of the traditional cultural dances of society Pantai Hambawang Timur is bagipang dance. Bagipang dance is a genetic inheritance that needs to preserve. This dance performance uses a piggyback made of bamboo with distinctive make-up and fashion, and accompanied by gamelan music. The purpose of this research is to know the forms and mathematical concepts that exist in bagipang dance equipment, and this research method is qualitative with an ethnographic approach. The result of the study shows that there are regular geometric shapes, that is: (1) rectangles; (2) rhombus; (3) trapezoid with isosceles; (4) equilateral triangles and isosceles; (5) circles; (6) sphere; and (7) half sphere, there was something irregular in the shape of the gypsy horse. There are mathematical concepts in bagipang dance equipment, that is: (1) numbers; (2) constant function; (3) periodic function; (4) reflection ; (5) set; (6) volume of rotary object; (7) volume measurement in liters; (8) volume with glass units; and (9) volume of cones with glass units. One example of a mathematical concept is the concept of numbers. The numbers we know are zero, one, two, three, four, five six, seven, eight, nine. While a number is an arrangement of numbers that have a specific value. Numbers consist of one number we know by unit, the two numbers we know with tens, three numbers that we know by hundreds, and so on.

Keywords: ethnomathematics, bagipang dance equipment, Pantai Hambawang Timur people

Cara Sitasi: Dewi, S., Jabar, A., \& Gazali, R.Y. (2019). Etnomatematika pada perlengkapan tari bagipang masyarakat Pantai Hambawang Timur. Math Didactic: Jurnal Pendidikan Matematika, 5(1), 13-22. https://doi.org/10.33654/math.v5i1.467 
Pertunjukkan tari bagipang oleh masyarakat Pantai Hambawang Timur di Kecamatan Labuan Amas Selatan, Kabupaten Hulu Sungai Tengah, Provinsi Kalimantan Selatan, merupakan kebiasaan unik yang bersifat warisan turun-temurun dari nenek moyang ke generasi berikutnya yang sangat dikenal oleh masyarakat. Penampilan tarian ini memakai seekor kuda-kudaan yang terbuat dari bambu, dengan tata rias dan tata busana yang khas, diiringi dengan musik gamelan.

Ketika budaya, matematika dan pendidikan dikombinasikan, pencampuran ini sering kali dinamakan ethnomathematics. Banyak masyarakat mempunyai tradisi-tradisi matematika yang berbeda dan telah mengembangkan bermacam-macam bidang pemikiran matematika (Walle, 2006: 104).

\section{Metode Penelitian}

Penelitian menggunakan pendekatan kualitatif dengan jenis penelitian etnografi. Berisi jenis penelitian, waktu dan tempat penelitian, target/sasaran, subjek penelitian, prosedur, instrumen dan teknik analisis data serta hal-hal lain yang berkait dengan cara penelitiannya.

Metode penelitian kualitatif adalah metode penelitian yang berlandaskan pada filsafat postpositivisme, digunakan untuk meneliti pada kondisi obyek yang alamiah, (sebagai lawannya adalah eksperimen) dimana peneliti adalah sebagai instrumen kunci, pengambilan sampel sumber data dilakukan secara purposive dan snowbaal, teknik pengumpulan data dengan triangulasi (gabungan), analisis data makna bersifat induktif/kualitatif, dan hasil penelitian kualitatif lebih menekankan dari pada generalisasi (Sugiyono, 2012: 15).

Jenis penelitian ini menggunakan etnografi. Menurut Moleong (dalam Zakiah, 2008: 183) istilah etnografi berasal dari kata ethno yang berarti bangsa dan graphy yang berarti menguraikan. Jadi berdasarkan asal katanya, etnografi berarti usaha untuk menguraikan kebudayaan atau aspek-aspek kebudayaan. Menurut Emzir (2011: 143) etnografi adalah suatu bentuk penelitian yang dapat didekati titik pandang preservasi seni dan kebudayaan, penelitian etnografi berfokus pada aspek-aspek analitik ilmu sosial. Dalam fokus ini, penelitian etnografi merupakan suatu cabang dari antropologi budaya.

Subjek dalam penelitian ini meliputi ketua, wakil ketua dan anggota Sanggar.Penelitian ini dilakukan di Sanggar Seni Asam Rimbun Pantai Hambawang Timur. Prosedur pengumpulan data ini dengan wawancara, observasi dan dokumentasi.Teknik analisis data ini dengan reduksi data, penyajian data, pengambilan kesimpulan dan verifikasi data.Keabsahan data yang digunakan dalam penelitian ini menggunakan teknik triangulasi. Triangulasi dilakukan agar hasil penelitian ini valid.

\section{Hasil Penelitian dan Pembahasan}

\section{Etnomatematika}

Menurut Zulkifli dan Dardiri (dalam Wahyuni \& Pertiwi, 2017: 113) secara bahasa, etnomatematika terdiri tiga kata yaitu awalan "etno" yang artinya sesuatu yang sangat luas yang mengacu pada konteks sosial budaya, termasuk bahasa, jargon, kode perilaku, mitos, dan simbol. Yang kedua kata dasar "mathema" cenderung berarti menjelaskan, mengetahui, memahami, dan melakukan kegiatan seperti 
pengkodean, mengukur, mengklasifikasi, menyimpulkan, dan yang terakhir pemodelan. Akhiran "tik" berasal dari techne, dan bermakna sama seperti teknik.

Menurut Barton (dalam Wahyuni\& Pertiwi, 2017:114) ethnomathematics mencakup ide-ide matematika, pemikiran dan praktik yangdikembangkan oleh semua budaya.Ethnomathematics juga dapat dianggap sebagaisebuah program yang bertujuan untuk mempelajari bagaimana siswa untuk memahami, mengartikulasikan, mengolah dan akhirnya menggunakan ide-ide matematika, konsep dan praktik-praktik yang dapat memecahkan masalah yang berkaitan dengan aktivitas sehari-hari mereka.

Dari definisi di atas dapat disimpulkan bahwa etnomatematika merupakan suatu teknik atau gaya yang menjelaskan tentang matematika yang tumbuh dan berkembang dalam kebudayaan,menggunakan konsep matematika secara luas yang terkait dengan berbagai aktivitas matematika. Aktivitas itu meliputi mengelompokkan, berhitung, mengukur, merancang bangunan atau alat, bermain, menentukan lokasi, dan lain sebagainya.

\section{Konsep Matematika}

Menurut As'ari, dkk (2016: 12-13) perkembangan matematika, bermula darikepekaanserta

kesadaranataupunkepedulianmanusia untuk memahamifenomena-fenomena

empirisyangditemuidalamkehidupan

keseharian. Bermunculanlah konsep-konsep dasar yang selanjutnya mengalami perluasan (ekspansi), pembenaran (justification), pembenahan,

sertageneralisasiatauformalisasi.Konsepmate matika disajikandengan bahasayang jelasdanspesifik.Bahasamatematika(yang digunakandalam matematika) sangat efisien dan merupakan alat yang ampuh untuk menyatakan konsep-konsep matematika.

Konsep dalam matematika merupakan suatu ide abstrak yang digunakan untuk melakukan klasifikasi atau penggolongan atau pengelompokkan terhadap objek. Dengan adanya suatu konsep, dapat diterangkan apakah sesuatu termasuk atau merupakan contoh atau bukan contoh dari ide tersebut.Pada umumnya konsep dalam matematika disusun dari konsep-konsep terdahulu atau fakta.

Dari uraian yang telahdisampaikan,makadapat dikatakan konsepmatematikamerupakan suatu ideabstrakyang digunakan untuk melakukan klasifikasi atau penggolongan atau pengelompokkan terhadap objek.

\section{Nilai-nilai Budaya}

Menurut Abdi (2009: 239) budaya merupakan sebuah sistem tentang cara hidup, cara berperilaku, cara berpikir, cara mempercayai, dan cara berhubungan dengan orang lain. Oleh karena itu, tidak salah jika dikatakan bahwa budaya yang menentukan bagaimana cara orang dalam bertindak atau berperilaku, dimana salah satu unsur pembentuk budaya tersebut adalah nilai-nilai (values). Menurut Muhaimin (dalam Fata, 2015: 303) nilai adalah suatu keyakinan atau kepercayaan yang menjadi dasar bagi seseorang atau sekelompok orang untuk memilih tindakannya atau menilai suatu yang bermakna bagi kehidupannya.Keyakinan atau kepercayaan yang mencerminkan nilai tersebut membentuk suatu kebudayaan yang diwariskan secara turun-temurun oleh masyarakat pemiliknya.Sehingga, budaya dan kehidupan manusia menjadi sebuah kenyataan 
yang tidak bisa dipisahkan.Aktivitas budaya sangat memengaruhi kualitas kehidupan manusia.

Dari uraian yang telah disampaikan, dapat disimpulkan bahwa nilai-nilai budaya adalah nilai-nilai yang bersumber dari keyakinan seseorang atau sekelompok orang untuk menilai suatu yang bermakna bagi kehidupannya.Keyakinan itu diwariskan secara turun-temurun kegenerasi berikutnya.

\section{Perlengkapan Tari Bagipang}

Pelaksanaaanpada pertunjukkan tari bagipang memerlukan berbagai persiapan, peralataan serta perlengkapan yang mempunyai bentuk geometri, konsep matematika dan nilai makna yang terkandung pada perlengkapan tersebut. Adapun perlengkapan tari bagipang yang harus disiapkan sebagai berikut.

\section{Babun (gendang)}

Nilai makna pada babun (gendang) ini memanggil tokoh-tokoh gaib, keinginan (perasaan) agar para arwah nenek moyang dapat hadir dalam pertunjukkan tari bagipang.Fungsi benda putar terbentuk oleh perputaran sebuah luas bidang terhadap sebuah garis yang sebidang, disebut sumbu putar. Daerah yang dibatasi kurva $y=\mathrm{f}(\mathrm{x})$, sumbu- $x$, garis $\mathrm{x}=\mathrm{a}$ dan $\mathrm{x}=\mathrm{b}$ diputar $360^{\circ}$ mengelilingi sumbu- $x$ sehingga mendekati bentuk dari babun (konsep volume benda putar). Sementara tali untuk bingkai atau pengikat kulit pada kayu dibuat dari rotan berbentuk belah ketupat, segitiga sama sisi dan gabungan dari dua buah bangun yaitu pesegi panjang dan segitiga sama sisi.
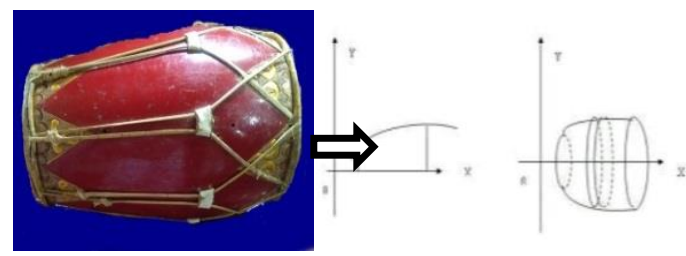

Gambar 1.Fungsi Sebuah Benda Putar mengelilingi Sumbu- $x$ mendekati Bentuk dari Babun (gendang)

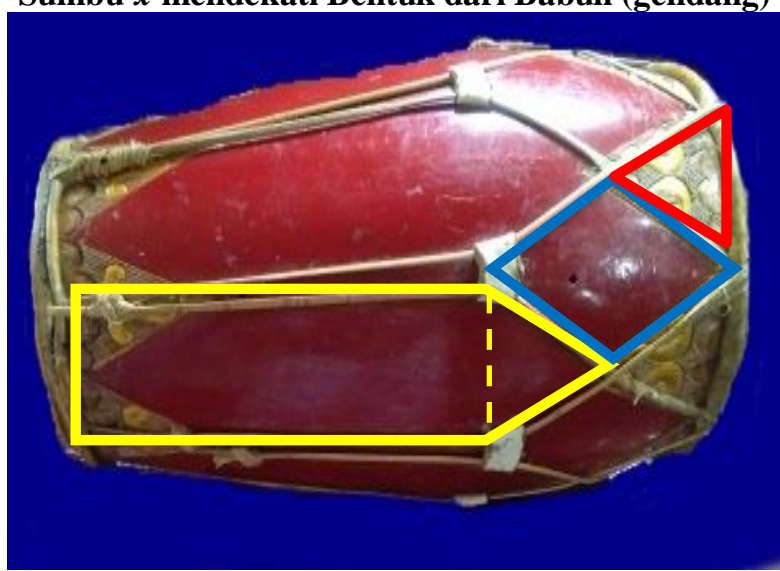

Gambar 2. Bingkai Babun (gendang) Belah Ketupat, Segitiga Sama Sisi dan Gabungan dari Dua Buah Bangun Yaitu Persegi Panjang dan Segitiga Sama Sisi

\section{Ketopong}

Melambangkan karakter seseorang, menonjolkan sikap kebijaksanaan seorang raja atau prajurit raja yang penyabar ataupun pemarah.Satu ketopong dipakai untuk satu orang penari tari bagipang (konsep fungsi konstan).

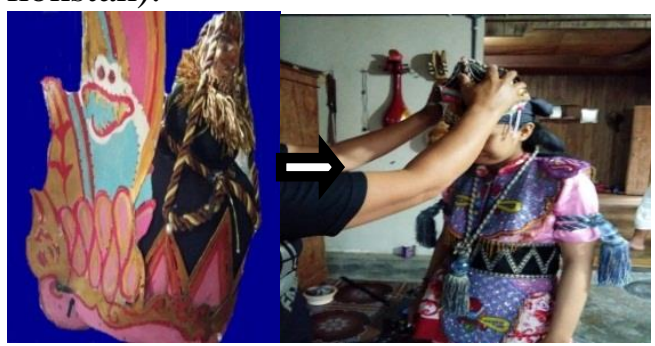

Gambar 3. Ketopong yang dipakai Sesuai Banyaknya Para Penari Tari Bagipang

\section{Ikat Kepala}

Penambah semangat bagi para penari yang melaksanakan pertunjukkan tari bagipang.Meskipun pertunjukkan tari bagipang tersebut banyak gerakkan, tetapi para penari tidak merasakan kelelahan.Ikat kepala yang terbuat dari kain berwarna hitam, yang diikatkan pada kepala berbentuk persegi panjang. 


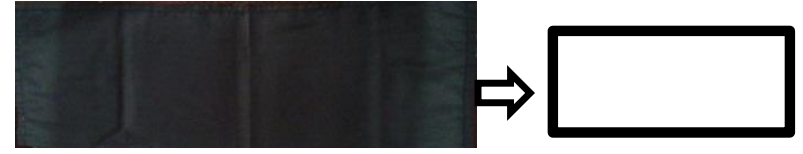

Gambar 4. Ikat kepala berbentuk Persegi Panjang

\section{Laung}

Makna dari laung ini sebagai penambah semangat dan gairah para penari tari bagipang, mereka tidak merasakan lelah tetapi mereka merasa semangat dan gairah dalam pertunjukkan tersebut.Laung ini wajib di pakai para penari tari bagipang, yang bentuknya pun juga mirip dengan ikat kepala, hanya laung ini lebih besar dari ikat kepala.Menggunakan sifat bayangan cermin dari titik-titik yang dipindahkan pada laung (konsep pencerminan).

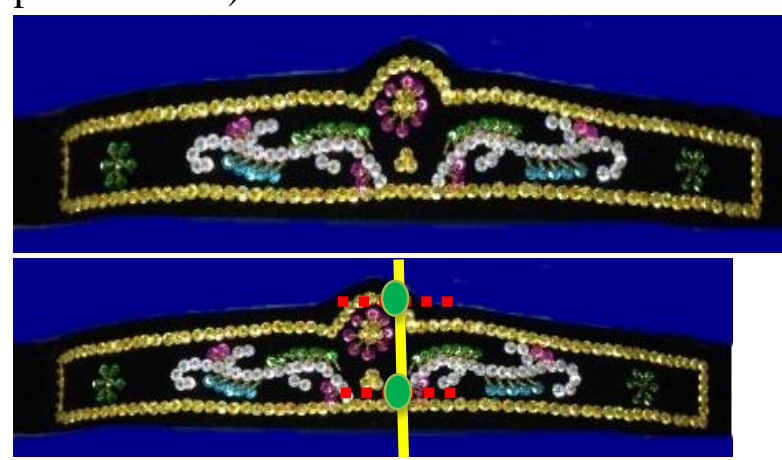

Gambar 5. Laung dengan Konsep Pencerminan

\section{Kikida}

Melambangkan baju para raja yang berani membelakebenaran, sebagai seorang pemimpin yang menjadi panutan bagi prajurit dan rakyatnya.Manik-manik yang dibentuk menjadi kikida, bentuk muka dan belakang dari kikida sama, dengan menggunakan sifat bayangan cermin dari titik-titik yang dipindahkan pada kikida (konsep pencerminan).

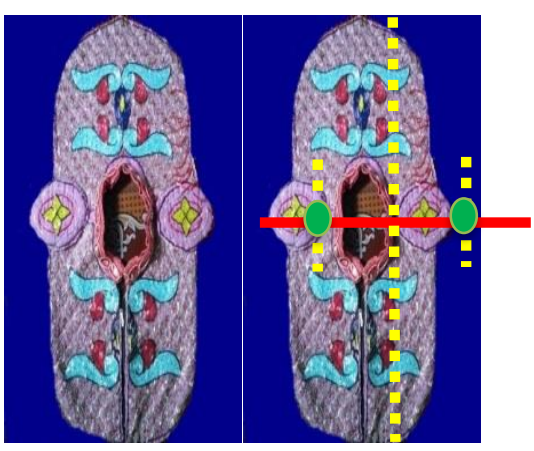

Gambar 6. Kikida dengan Konsep Pencerminan

\section{Sabuk}

Sabuk sebagai pembeda dari kerajaan satu dengan kerajaan yang lainnya. Melambangkan kesatria yang gagah dan berani dalam membela kebenaran. Sabuk terbuat dari kain yang berbentuk persegi panjang dihiasi manik-manik dengan motif segitiga sama kaki.

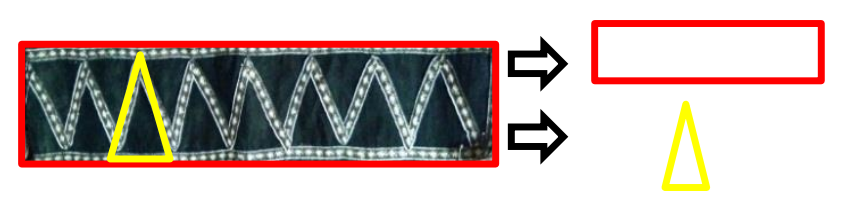

Gambar 7. Sabuk berbentuk Persegi Panjang dengan Motif Segitiga Sama Kaki

\section{Selendang}

Selendang berbentuk persegi panjang dililit pada bagian pinggul hingga lutut pada penari tari bagipang. Selendang ini sebagai simbol kemenangan.

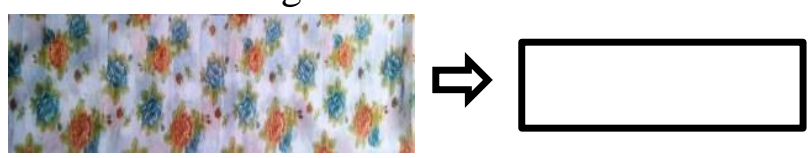

Gambar 8. Selendang berbentuk Persegi Panjang

\section{Ingkal Kaki (bingkap)}

Ingkal kaki (bingkap) sebagai pelindung dari serangan musuh, makna dari ingkal kaki ini sebagai pelindung dari hal-hal negatif yang akan mencelakakan dirinya sendiri.Ingkal kaki (bingkap) berbentuk trapesium sama kaki terbuat dari kain yang dihiasi manik-manik dengan motif grafik 
seperti wayang kulit dan bentuk kuda hanya dapat dilihat dari samping, tetapi tanpa kaki. Cara menggunakan properti ini dengan cara diletakkan pada disela-sela ketiak atau dikapit. Properti digerakkan naik turun dan juga kepala dari kuda gipang digerakkan ke kiri dan ke kanan. Kuda gipang melambangkan suatu sifat keperkasaan yang gagah, berani, bijaksana, semangat dan pantang menyerah dalam kondisi apapun.

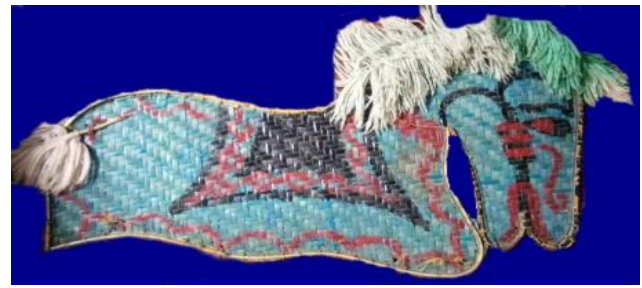

Gambar 13. Kuda gipang yang terbuat dari Anyaman Bambu berbentuk Bangun Geometri Tak Beraturan

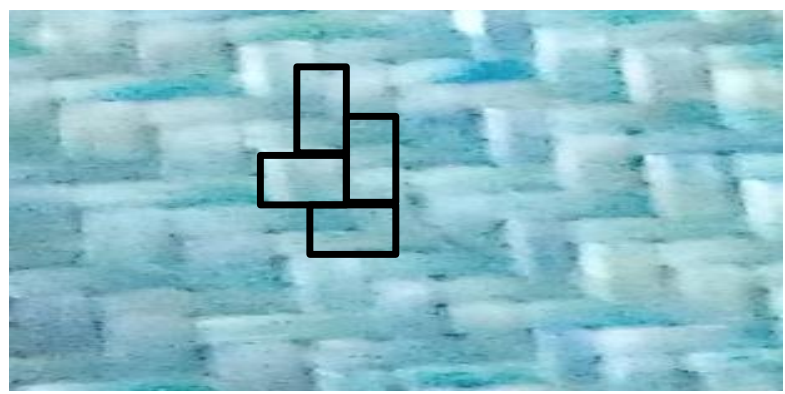

Gambar 14. Kuda Gipang dengan Motif Anyaman berbentuk Persegi Panjang

\section{Beras}

Beras yang harus disiapkan sebanyak lima liter (konsep pengukuran volume dengan satuan liter) sebelum pertunjukkan tari bagipang dimulai. Beras ini yang akan diserahkan sebagai persembahan bagi para arwah nenek moyang yang hadir dalam pertunjukkan tari bagipang tersebut.

Beras ini juga yang dijadikan sebagai proses ritual yang akan ditaburkan di atas kepala para penari tari bagipang. Makna dari beras adalah bahwa manusia terlahir ke dunia ini dalam keadaan suci tidak berdosa dan batin yang suci. Suatu permohonan agar diberikan 
keselamatan dan kelancaran ketika pertunjukkan tari bagipang berlangsung.

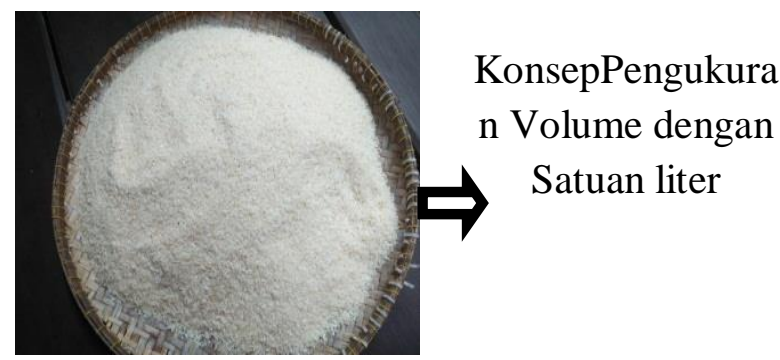

Gambar 15. Beras Lima Liter

\section{Kopi (Manis dan Pahit)}

Air kopi yang disediakan satu gelas (konsep volume dengan satuan gelas) pakai gula dan satu gelas (konsepvolume dengan satuan gelas) tanpa gula. Air kopi (manis dan pahit) ini adalah minuman yang dipersembahkan kepada para makhluk halus atau tokoh-tokoh gaib. Minuman ini sangat disukai para makhluk halus atau tokoh-tokoh gaib, minuman ini yang selalu disediakan untuk para arwah nenek moyang.

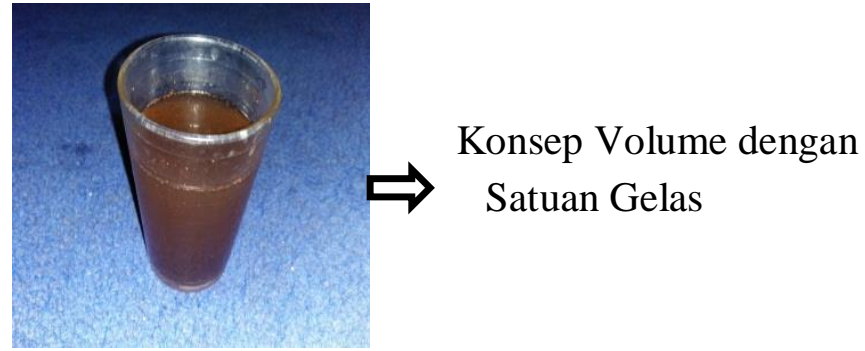

Gambar 16. 1 Gelas Kopi Manis

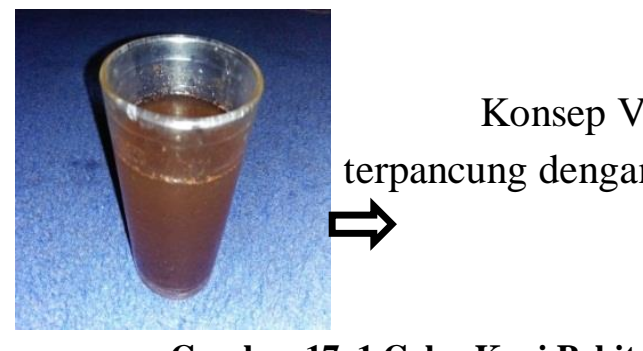

Perapen
Perapen adalah tempat pembakaran wangi-wangian atau harum-haruman yang digunakan sebagai proses ritual dalam penyerahan piduduk (sesajen), untuk memanggil makhluk halus atau tokoh-tokoh gaib. Bentuk perapen setengah bola yang di isi dengan arang untuk dibakar.
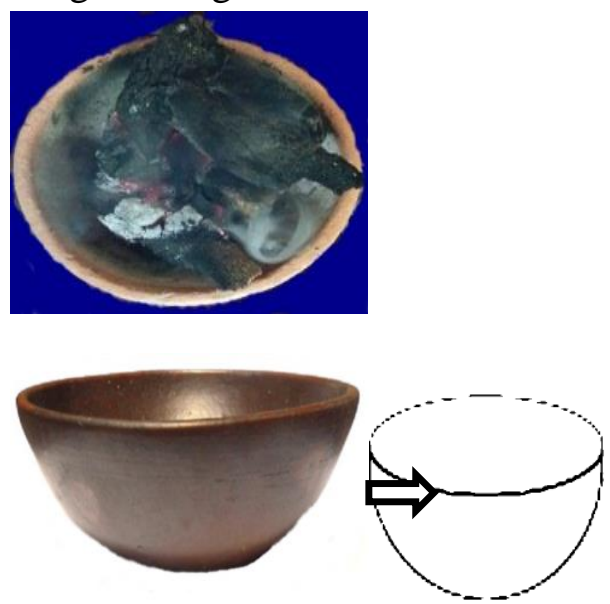

Gambar 18. Perapen berbentuk Setengah Bola

\section{Manyan}

Pelaksanaan ritual sebelum pertunjukkan tari bagipang manyan yang berbentuk persegi panjang ditumbuk kemudian ditaburkan dalam perapen, yang sudah diisi bara api sebagai proses ritual sebelum pertunjukkan tari bagipang dimulai. Wangi dari manyan yang dibakar di dalam perapen ini dimaksudkan untuk menghapus dosa-dosa yang pernah dilakukan. Sebagai wujud keharuman diri manusia, yang artinya manusia harus menjaga keharuman namanya agar tidak terpengaruh oleh hal-hal yang negatif.

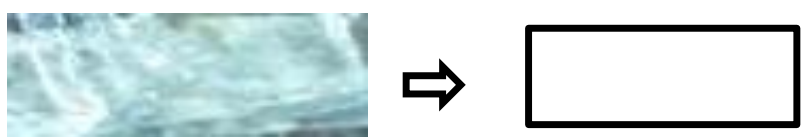

Gambar 19. Manyan berbentuk Persegi Panjang

Proses Ritual 
Sebelum pertunjukkan dimulai biasanya Sanggar Seni Asam Rimbun melakukan proses ritual agar pertunjukkan tari bagipang berjalan dengan lancar dan diberikan keselamatan. Proses ritual yang dilakukan di Sanggar Seni Asam Rimbun sebagai berikut.

1. Mengumpulkan semua perlengkapan berupa tata rias dan tata busana tari bagipang agar pertunjukkan tari bagipang berjalan dengan lancar dan diberikan keselamatan (konsep himpunan). Maknanya agar semua perlengkapan tari bagipang yang dikenakan para tari bagipang dapat membawa keselamatan bagi dirinya.

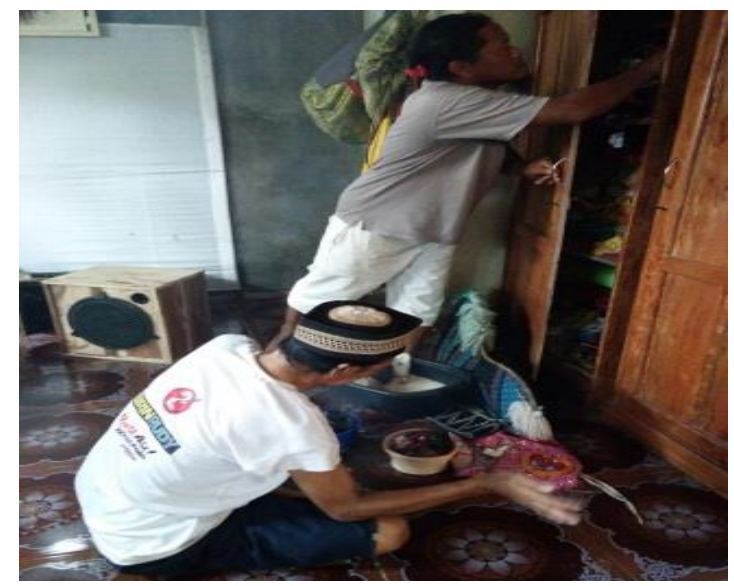

Gambar 20.Mengumpulkan semua perlengkapan berupa tata rias dan tata busana tari bagipang

2. Mengumpulkan semua piduduk atau sesajen untuk diserahkan pada makhluk halus atau tokoh-tokoh gaib (konsep himpunan). Maknanya piduduk atau sesajen untuk dipersembahkan kepada roh nenek moyang mereka yang hadir pada pertunjukkan tari bagipang tersebut.

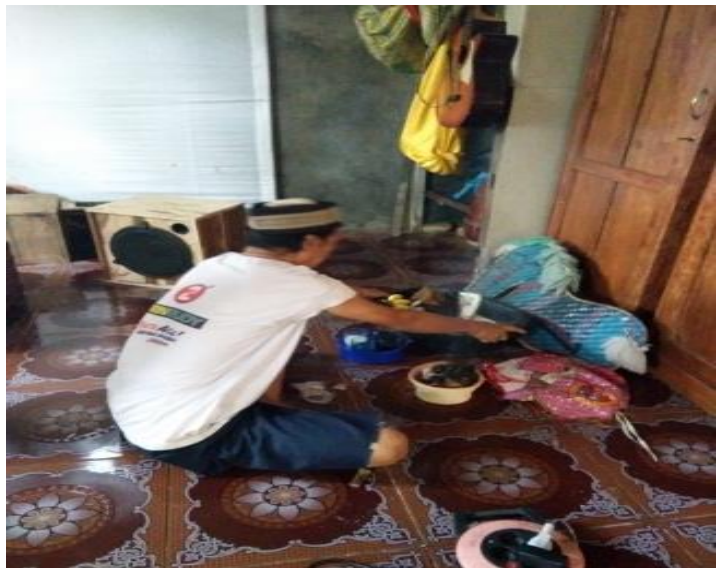

Gambar 21. Mengumpulkan semua piduduk atau sesajen

3. Menyerahkan piduduk atau sesajen dengan mengangkat piduduk atau sesajen itu mengelilingi di atas perapen yang ditaburi manyan sebanyak tiga kali (konsep bilangan). Maknanya untuk memanggil makhluk halus atau roh nenek moyang mereka sebagai tanda penghormatan terhadap nenek moyang mereka yang hadir pada pertunjukkan tari bagipang tersebut.

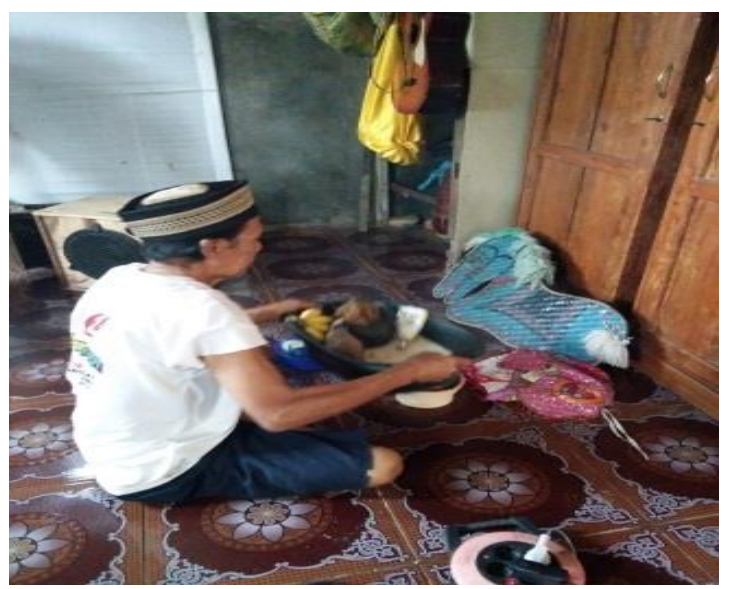

Gambar 22. Menyerahkan piduduk atau sesajen

4. Membaca mantra sebanyak tiga kali (konsep bilangan). Maknanya suatu permohonan atau pengharapan agar pertunjukkan tari bagipang berjalan dengan lancar, dan diberikan keselamatan. 


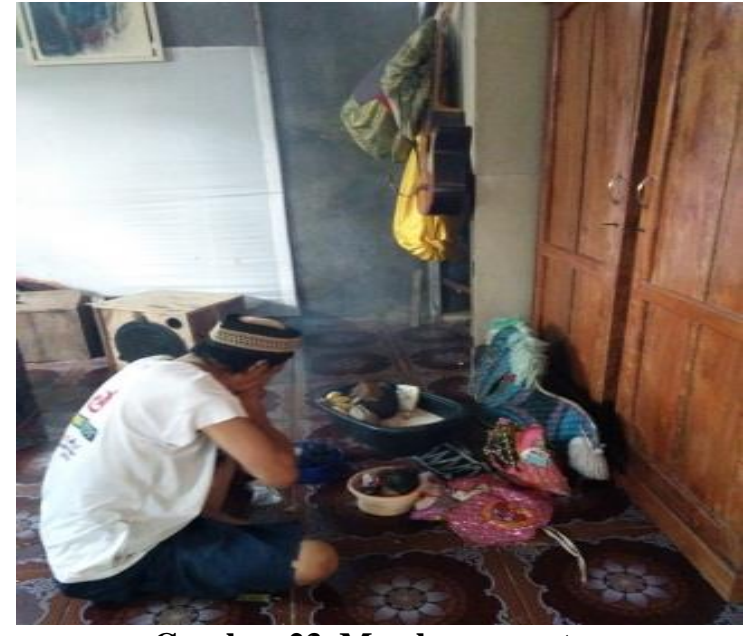

Gambar 23. Membaca mantra

5. Menaburi beras kepada semua anggota Sanggar Seni Asam Rimbun khususnya para penari tari bagipang sebanyak tiga kali (konsep bilangan). Maknanya agar para penari tari bagipang dihindarkan dari berbagai macam bahaya.

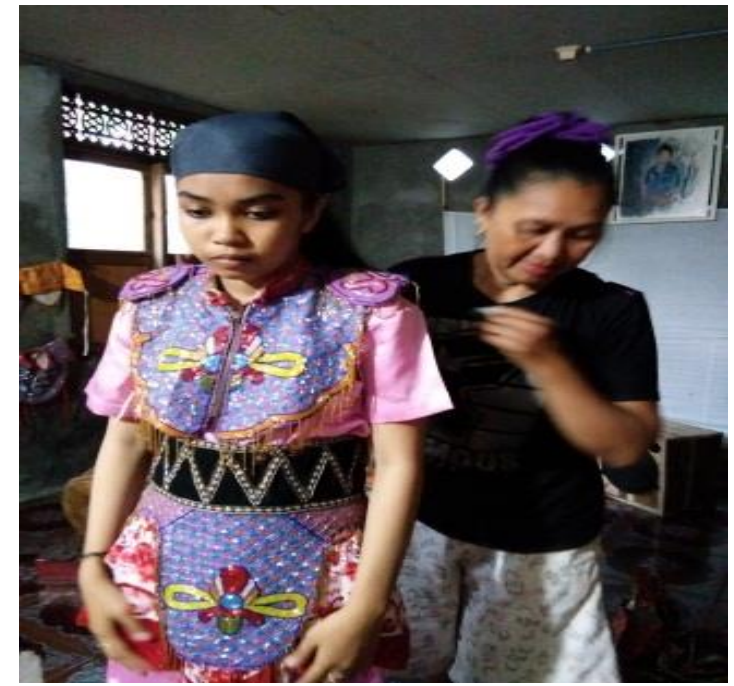

Gambar 24. Menaburi beras

\section{Simpulan dan Saran}

\section{Simpulan}

Perlengkapan tari bagipang terdapat bentuk-bentuk geometri yang beraturan seperti persegi panjang, belah ketupat, trapesium sama kaki, segitiga sama sisi dan sama kaki, lingkaran, bola dan setengah bola, adapun bentuk geometri tak beraturan terdapat pada bentuk kuda gipangnya. Ada konsepkonsepmatematika pada perlengkapan tari bagipang seperti konsep bilangan, fungsi konstan, fungsi periodik, refleksi, himpunan, volume benda putar, pengukuran volume dengan satuan liter, volume dengan satuan gelas dan volume kerucut terpancung dengan satuan gelas.

\section{Saran}

Masyarakat diharapkan menemukan
ilmu pengetahuan baru tentang etnomatematika pada perlengkapan yang digunakan di pertunjukkan tari bagipang. Masyarakat diharapkan agar tetap menjaga dan melestarikan kebudayaan warisan turuntemurun dari nenek moyang, karena matematika sampai kapan pun tidak terlepas dari budaya dan nilai yang telah ada pada masyarakat.

\section{Daftar Pustaka}

Abdi, Rahmani. 2009. Membangun Nilai-nilai Budaya dalam Pendidikan: Inspirasi dari Novel "Sang Pemimpi" Karya Andrea Hirata. Jurnal Al-Risalah, Vol.5, No.2: hlm 239.

As'ari, Abdur Rahman, dkk. 2016. Buku Guru Matematika: SMP/MTs Kelas VIII. Jakarta: Kementerian Pendidikan dan Kebudayaan.

Emzir. 2011. Metodologi Penelitian Pendidikan: Kuantitatif dan Kualitatif. Jakarta: PT Raja Grafindo Persada.

Fata, M. Triono Al. 2015. Manifestasi Budaya dalam Pendidikan Islam: Membangun Intelektualisme Budaya dengan Nilai-nilai Pendidikan Islam. Jurnal Pendidikan dan Pembelajaran, Vol. 10, No. 2: hlm 303-307. 
Rohimah, Iim \& Nursuprianah, Indah. 2016.

Pengaruh Pemahaman

KonsepGeometri Terhadap

Kemampuan Siswa dalam

Menyelesaikan Soal-Soal Bidang

Datar (Studi Kasus Kelas VII di Smp

Negeri 1 Cidahu Kabupaten

Kuningan). Jurnal Pendidikan

Matematika, Vol. 5, No. 1: hlm 21.

Sugiyono. 2012. Metode Penelitian

Pendidikan Pendekatan Kuantitatif,

Kualitatif, dan R\&D. Bandung:

Alfabeta.

Wahyuni, Asri, \& Pertiwi, Surgawi. 2017.

Etnomatematika dalam Ragam Hias

Melayu. Math Didactic: Jurnal

Pendidikan Matematika, Vol.3,

No.2, hlm 113-115.

Walle, Johan A. Van De. 2006. Matematika

Sekolah Dasar dan Menengah Edisi

Keenam. Jakarta: PT Gelora Aksara

Pratama.

Zakiah, Kiki. 2008. Penelitian Etnografi

Komunikasi Tipe Dan Metode.

Jurnal Penelitian Etnografi.Vol.09,

No.01: hlm 183. 